\title{
Interactions between Candida species and platelets
}

\author{
M. D. P. WILLCOX* $\dagger$, B. C. WEBB $\dagger$, A. THAKUR* and D. W. S. HARTY† \\ * Cornea and Contact Lens Research Unit, School of Optometry and Cooperative Research Centre for Eye \\ Research and Technology, University of New South Wales, NSW 2052 and †Institute of Dental Research, \\ Sydney, NSW 2010, Australia
}

\begin{abstract}
Candida spp. are able to cause disseminated disease in immunocompromised patients. This study examined the interactions of Candida spp. with platelets, complement and polymorphonuclear leucocytes (PMNLs). With the exception of $C$. albicans, all other Candida spp., including a $C$. albicans strain previously classified as $C$. stellatoidia, aggregated human platelets at a ratio of yeast cells: platelets of 1:80. Usually, those species and strains that aggregated platelets were either killed or prevented from growing in platelet-rich plasma indicating that the aggregation released microbicidal or microbistatic substances that were active against Candida spp. All Candida spp. were resistant to attack by complement in $50 \%$ serum. However, all species activated complement as determined by the presence of $\mathrm{C3}$ fragments on their surface, in particular a 195-kDa fragment corresponding to C3c, two fragments at 67 and $40 \mathrm{kDa}$ corresponding to $\mathrm{iC} 3 \mathrm{~b}$, and a $33-\mathrm{kDa}$ fragment corresponding to $\mathrm{C} 3 \mathrm{~d}$. When strains were tested for their ability to stimulate the release of pro-inflammatory substances from platelets and PMNLs, it was found that most strains stimulated PMNLs to release interleukin(IL)-8 but not IL-1 $\beta$ or leucotriene $B_{4}$. The ability of $C$. albicans to evade complement-mediated killing and not to aggregate platelets may contribute to the survival of this species in the blood during vascular infections.
\end{abstract}

\section{Introduction}

Candida spp. are important opportunist pathogens that infect medically compromised individuals. The most common oral disease caused by Candida spp. is denture stomatitis. Although all species of Candida can produce denature stomatitis, the most commonly isolated species is C. albicans [1]. C. albicans is the commonest of the Candida spp. found within the oral cavity; other species that have been isolated include $C$. glabrata, C. tropicalis, C. guilliermondii and C. krusei [2]. However, if Candida spp. enter the blood stream, they can cause severe life-threatening diseases such as infective endocarditis, vascular catheter sepsis and infections of vascular prostheses [3, 4]. Several species of Candida have been isolated from patients with endocarditis, with $C$. albicans being the most common, followed by C. parapsilosis, C. tropicalis, C. stellatoidia (currently classified in the species $C$. albicans) and C. krusei $[1,5,6]$.

Received 15 April 1997; revised version received 26 June 1997; accepted 1 July 1997.

Corresponding author: Dr M. D. P. Willcox.
The mechanisms utilised by Candida spp. to initiate vascular infections are believed to be complex, involving interactions of fungal cells with plasma proteins, e.g., fibronectin [7], endothelial cells [8] and platelets [9], and avoidance of plasma host defences such as complement and phagocytosis. It is well known that Candida cells can activate the alternative complement pathway, a major effector pathway of inflammation, and this will release the inflammatory mediators $\mathrm{C} 3 \mathrm{a}$ which is vasodilatory, and C5a which activates and recruits white blood cells to sites of infection. Recently, it has been demonstrated that activation of complement on the surface of Streptococcus sanguis may be involved in platelet aggregation [10]. Activation of white blood cells, e.g., polymorphonuclear leucocytes (PMNLs), macrophages, mast cells and platelets also releases inflammatory mediators, e.g., histamine and arachidonic acid metabolites and antimicrobial peptides such as human neutrophil peptides $[11,12]$ and platelet microbicidal proteins [13]. It has been clearly demonstrated that PMNLs are of vital importance in preventing the development of candidosis [14]. The aim of this investigation was to examine different species of Candida for their ability to interact with these elements of the host defence system. 


\section{Materials and methods}

\section{Candida strains and growth conditions}

All strains were obtained from the culture collection of the Institute of Dental Research, Sydney, Australia. $C$. albicans NCYC 1473 (GRI 682) was originally isolated from a cervical smear, C. albicans NCYC 1467 (GDH 2346) was isolated from the mouth of a patient with denture stomatitis, C. albicans Y5499 and C. albicans (formerly stellatoidia) Y523, C. tropicalis Y9, C. parapsilosis $\mathrm{Y} 316$, C. krusei $\mathrm{Y} 301$, C. kefyr Y83 and C. guilliermondii $\mathrm{Y} 324$ were all isolated from the saliva of patients attending the United Dental Hospital of Sydney. All strains were grown for $24 \mathrm{~h}$ in Sabouraud's broth (containing Neopeptone $10 \mathrm{~g} / \mathrm{L}$, glucose $40 \mathrm{~g} / \mathrm{L} ; \mathrm{pH} 5.6$ ), cells were harvested by centrifugation (10 min, $3000 \mathrm{~g}$ ), washed three times in phosphate-buffered saline (PBS; $\mathrm{NaCl} 8.0 \mathrm{~g} / \mathrm{L}, \mathrm{KCl}$ $0.2 \mathrm{~g} / \mathrm{L}, \mathrm{Na}_{2} \mathrm{HPO}_{4} 1.15 \mathrm{~g} / \mathrm{L}, \mathrm{KH}_{2} \mathrm{PO}_{4} 0.2 \mathrm{~g} / \mathrm{L}, \mathrm{pH} 7.4$ ) and finally resuspended in PBS to an $\mathrm{OD}_{600}$ of 1.0 $\left(1.5 \times 10^{6} \mathrm{cfu} / \mathrm{ml}\right)$, unless otherwise stated.

\section{Interactions of Candida cells with platelets}

Two methods were used to assess the interaction of Candida cells with platelets. Firstly, the ability of Candida spp. to aggregate platelets was measured and secondly the ability of platelet-rich plasma (PRP) to kill Candida spp. was determined. PRP was obtained from whole citrated blood by centrifugation for $10 \mathrm{~min}$ at $250 \mathrm{~g}$ and removal of the supernate. Platelet-poor plasma (PPP) was obtained by recentrifugation of the pellet from the PRP for $10 \mathrm{~min}$ at $3000 \mathrm{~g}$ and removal of the supernate.

For examination of the ability of Candida spp. to aggregate platelets, Candida cells were mixed with platelets $\left(2.5 \times 10^{8}\right.$ platelets $\left./ \mathrm{ml}\right)$ in differing ratios of Candida cells to platelets, ranging from 1:1000 to $1: 10$, by concentration of the Candida cells by centrifugation, or dilution of the cells in PBS. In either a single-channel recording platelet aggregometer (Model 430; Chrono-log Corporation, Havertown, PA, USA) or a dual-channel aggregometer (Model 540), Candida cells and platelets were mixed and allowed to interact at $37^{\circ} \mathrm{C}$ for $25 \mathrm{~min}$. Aggregation was recorded as a drop in the OD. Adenosine diphosphate (ADP), a natural agonist, was added after incubation for $22 \mathrm{~min}$ to measure platelet function and also the degree of aggregation caused by Candida spp.

Potential inhibitors (Sigma Aldrich, Sydney, Australia) were dissolved in PBS and added to plasma to the following final concentrations: $40 \mathrm{mM}$ disodium ethylene-diamine-tetra-acetic acid (EDTA), apyrase (grade V) $10 \mathrm{mg} / \mathrm{mL}, 1 \mathrm{mM}$ quinacrine or $2 \mathrm{mM}$ imipramine. The inhibitors $(25 \mu \mathrm{l})$ were added to both PPP and PRP, incubated at ambient temperature for $10 \mathrm{~min}$ and then incubated at $37^{\circ} \mathrm{C}$ for $5 \mathrm{~min}$ before the addition of Candida cells. Platelet aggregation was then measured. The control consisted of $25 \mu \mathrm{l}$ of PBS. An examination of the ability of platelets obtained from different blood group subjects was also performed, with subjects who were A positive, A negative, $\mathrm{B}$ positive, $\mathrm{O}$ negative, $\mathrm{O}$ positive and $\mathrm{AB}$ negative.

For examination of the ability of platelets to kill Candida spp., PRP and Candida cells were mixed in the optimal ratio for platelet aggregation and incubated at $37^{\circ} \mathrm{C}$ for $4 \mathrm{~h}$ with end-over-end rotation. At time 0 and after $30 \mathrm{~min}, 1 \mathrm{~h}$ and $4 \mathrm{~h}$, samples of the mixture were removed and a Miles and Misra plate assay [15] was performed to determine the number of viable Candida cfu. In addition, the numbers of yeast cells in clumps of yeast plus platelets was examined microscopically and this number was taken into account when the numbers of viable cfu were calculated in the Miles and Misra assay.

\section{Interaction of Candida spp. with complement}

Cells were allowed to interact with complement in two ways. Firstly, the ability of complement in serum to kill Candida cells was measured and secondly the ability of Candida cells to bind to complement component C3 was examined.

For determination of complement susceptibility, Candida cells were resuspended to an $\mathrm{OD}_{600}$ of 1.0 in Dulbecco's phosphate-buffered saline (CSL, Sydney, Australia) and then mixed with pooled normal human serum (obtained from four healthy donors) to give a final concentration of $50 \%$ serum. The mixtures were allowed to interact together at $35^{\circ} \mathrm{C}$ for $4 \mathrm{~h}$ with endover-end rotation; samples were removed at times 0 , $30 \mathrm{~min}, 1 \mathrm{~h}$ and $4 \mathrm{~h}$ after incubation. A Miles and Misra plate assay was then performed to determine the number of viable Candida cfu.

For examination of the binding and activation of complement $\mathrm{C} 3$ by Candida strains, the method of Gordon et al. [16] was used. Briefly, Candida cells were opsonised in serum $50 \%$ for $1 \mathrm{~h}$ at $35^{\circ} \mathrm{C}$, then washed three times in PBS containing sodium dodecylsulphate (SDS) $1 \% \mathrm{w} / \mathrm{v}$. Pellets were then resuspended in a solution of $1 \mathrm{M}$ hydroxylamine/SDS $1 \%$ and incubated for $1 \mathrm{~h}$ at $37^{\circ} \mathrm{C}$. The Candida cells were then removed by centrifugation and the supernate containing C3 fragments was collected and stored at $-70^{\circ} \mathrm{C}$. Before separation of $\mathrm{C} 3$ fragments by SDSPAGE, C3 fragments were reduced by boiling with $10 \mathrm{mM}$ dithiothreitol for $10 \mathrm{~min}$. SDS-PAGE was then performed with prepoured 4-20\% gradient gels (BioRad, Sydney, Australia). The separated proteins were then transferred to nitrocellulose membranes by Western blotting in Towbin's buffer. The membrane was blocked for $2 \mathrm{~h}$ in bovine serum albumin (Sigma Aldrich) $1 \% \mathrm{w} / \mathrm{v}$ in PBS containing Tween $200.05 \%$ $\mathrm{v} / \mathrm{v}$. Subsequently, a 1 in 100 dilution of sheep 
antiserum to human $\mathrm{C} 3 \mathrm{c}$ (The Binding Site; Birmingham) in PBS containing Tween $200.05 \%$ (PBST) was added to the membrane and incubated at ambient temperature for $4 \mathrm{~h}$. After washing three times in PBST, peroxidase-conjugated sheep antiserum to rabbit IgG (Sigma Aldrich; 1 in 500 dilution) was added and incubated for $1 \mathrm{~h}$ at ambient temperature. The nitrocellulose was then washed three times in PBS and developed with chloronaphthol (Sigma Aldrich) $12 \mathrm{mg}$ in methanol $25 \% \mathrm{v} / \mathrm{v}$ and $\mathrm{H}_{2} \mathrm{O}_{2} 0.001 \% \mathrm{v} / \mathrm{v}$ in PBS.

\section{Survival of Candida spp. in the presence of PMNLs}

Whole blood was collected in sodium heparin-treated Vacuettes (Greiner GesmbH, Kremsmunster, Austria) and separated with mono-poly resolving medium according to the manufacturer's instructions (ICN Biomedicals, Sydney, Australia). Briefly, $7 \mathrm{ml}$ of blood was layered on $6 \mathrm{ml}$ of mono-poly resolving medium and centrifuged at $400 \mathrm{~g}$ for $45 \mathrm{~min}$. Red blood cells were centrifuged through the mono-poly resolving medium, leaving monocytes and PMNLs in two distinct bands; PMNLs were the pipetted off with a sterile disposable Pasteur pipette. Purified PMNLs were washed three times by centrifugation at $250 \mathrm{~g}$ in PBS with heat inactivated fetal calf serum (CSL, Sydney, Australia) $10 \% \mathrm{v} / \mathrm{v}$. The PMNLs were then resuspended in DPBS plus glucose $0.1 \% \mathrm{w} / \mathrm{v}$ (DPBSG), counted on an automated cell counter (Sysmex NE8000, Sysmex, Kobe, Japan) and adjusted to $2 \times 10^{6} \mathrm{PMNLs} / \mathrm{ml}$. The purity of the preparation was checked and used when $>90 \%$ of white blood cells were PMNLs. After PMNLs had been equilibrated for $1 \mathrm{~h}$ at $4^{\circ} \mathrm{C}$, they were mixed with the Candida suspension at a ratio of 1 Candida cell to every 10 PMNL. The mixture was incubated for $4 \mathrm{~h}$ at $37^{\circ} \mathrm{C}$ with end-over-end rotation and samples were removed at time 0 , and after incubation for $1 \mathrm{~h}$ and $4 \mathrm{~h}$. A Miles and Misra plate assay was then performed to determine the number of viable Candida cfu. In addition, the numbers of yeast cells in clumps of yeast plus PMNLs was examined microscopically and this number was taken into account when the number of cfu, were calculated in the Miles and Misra assay.

\section{Release of inflammatory mediators}

The supernate from the interactions of Candida cells with either PMNLs or platelets were assayed for interleukin- $1 \beta$ (IL- $1 \beta$ ), IL- 8 and leucotriene $\beta_{4}\left(\mathrm{LTB}_{4}\right)$ with commercially available enzyme-linked immunosorbent assay (ELISA) kits obtained from R\&D systems, MN, USA (IL-1 $\beta$, IL-8) and Perspective diagnostics, MA, USA $\left(\mathrm{LTB}_{4}\right)$. Samples were tested for IL- $1 \beta$ and IL- 8 by an antibody sandwich principle. $\mathrm{LTB}_{4}$ was measured by competition inhibition ELISA. The methods for sample preparation and analysis followed protocols supplied by the manufacturers. Accurate sample concentration was calculated from the linear correlation made with standard antigen concentration versus absorbency. All strains were incubated for $30 \mathrm{~min}$ and $4 \mathrm{~h}$ with PMNLs at a ratio of 10 PMNLs to 1 Candida cell or platelets at a ratio of 1 Candida cell to 80 platelets and examined for the release of IL- 8 and $\mathrm{LTB}_{4}$. The release of IL- $1 \beta$ was determined only after incubation of $C$. albicans NCYC 1467, C. albicans (stellatoidia) Y523, C. kefyr Y83 and C. guilliermondii Y324 with PMNLs for $4 \mathrm{~h}$. Controls were PMNLs or platelets incubated without the addition of the yeast cells.

\section{Statistical analysis}

Correlations between data sets were analysed by Pearson's correlation coefficient.

\section{Results}

\section{Interactions of Candida spp. with platelets}

All strains, with the exception of $C$. albicans NCYC 1473, C. albicans NCYC 1467 and C. albicans Y5499, were able to aggregate platelets (Table 1); C. tropicalis Y9 aggregated platelets within the shortest incubation time. A Candida cell: platelet ratio of $<1: 80$ showed either no aggregation, a lag phase of $>25 \mathrm{~min}$, or $<100 \%$ aggregation when compared to ADP. At a Candida cell: platelet ratio of 1:80 strains showed minimal lag phase and final percentage aggregation approaching $100 \%$. For the higher ratios, the final percentage aggregations were $>100 \%$ indicating that both aggregation and agglutination of platelets was

Table 1. Aggregation of human platelets by Candida spp.

\begin{tabular}{lccc}
\hline $\begin{array}{l}\text { Species and } \\
\text { strain no. }\end{array}$ & $\begin{array}{c}\text { Mean (SD) lag } \\
\text { phase (min) }\end{array}$ & $\begin{array}{c}\text { Mean (SD) time } \\
\text { to maximum } \\
\text { aggregation (min) }\end{array}$ & $\begin{array}{c}\text { Mean (SD) } \\
\text { aggregation }^{\dagger}(\%)\end{array}$ \\
\hline C. albicans (stellatoidia) Y523 & $8.0(3.0)$ & $21.5(5.8)$ & $83(15)$ \\
C. tropicalis Y9 & $6.5(1.0)$ & $19.7(2.2)$ & $100(0)$ \\
C. parapsilosis Y316 & $10.4(1.8)$ & $16.1(3.8)$ & $97(5)$ \\
C. krusei Y301 & $15.7(2.6)$ & $21.8(4.1)$ & $100(0)$ \\
C. kefyr Y83 & $7.7(7.0)$ & $19.4(4.9)$ & $91(15)$ \\
C. guilliermondii Y324 & $14.0(6.8)$ & $18.2(7.6)$ & $100(0)$ \\
\hline
\end{tabular}

${ }^{*}$ Lag phase was the time for the trace to vary from baseline after addition of the Candida cells.

${ }^{\dagger}$ Percentage aggregation was determined by using the aggregation given by ADP as $100 \%$. 
occurring. Thus the optimum Candida cell: platelet ratio for those strains showing aggregation was 1:80. Fig. 1 demonstrates the aggregation profile of platelets in the presence of $C$. tropicalis Y9.

To test for mechanisms of platelet aggregation by Candida spp., several different inhibitors were used with $C$. tropicalis (Table 2). EDTA and imipramine were particularly potent inhibitors of aggregation, and quinacrine and apyrase were moderately antagonistic, reducing the final percentage aggregation to $60 \%$ and $35 \%$, respectively. The use of blood from different blood group donors did not affect the ability of Candida spp. to aggregate platelets, with Candida cells aggregating platelets from all blood groups.

Two strains, C. albicans (stellatoida) Y523 and $C$. tropicalis $\mathrm{Y} 9$ were killed in the presence of platelets, losing between 40 and $55 \%$ viability (Table 3, Fig. 2). C. parapsilosis $\mathrm{Y} 316, C$. krusei $\mathrm{Y} 301$ and C. kefyr Y83 were not killed in the PRP, but could not grow in

Table 2. The effect of platelet aggregation inhibitors on aggregation of human platelets by $C$. tropicalis $\mathrm{Y} 9$

\begin{tabular}{lcc}
\hline Inhibitor & $\begin{array}{c}\text { Lag phase } \\
(\mathrm{min})^{*}\end{array}$ & $\begin{array}{c}\text { Aggregation } \\
(\%)^{\dagger}\end{array}$ \\
\hline Control & 9.7 & 100 \\
EDTA & $>25$ & 0 \\
Imipramine & $>25$ & 0 \\
Quinacrine & 13.0 & 60 \\
Apyrase & 10.0 & 35 \\
\hline
\end{tabular}

${ }^{*}$ Lag phase was the time for the trace to vary from baseline after addition of the Candida.

${ }^{\dagger}$ Percentage aggregation was determined by using the aggregation given by $C$. tropicalis control (with no inhibitor present) as $100 \%$. this medium. All C. albicans strains produced hyphae in PRP. Fig. 2 demonstrates the effect of PRP, complement and PMNLs on two strains, C. albicans NCYC 1473 and $C$. tropicalis Y9. There was a negative correlation between survival in serum (complement) and survival in PRP $(p=0.047)$.

\section{Interactions of Candida spp. with complement}

All Candida spp. were resistant to the action of complement in serum, and most strains were able to grow after incubation for $4 \mathrm{~h}$ (Table 3). However, $C$. albicans NCYC 1473, NCYC 1467 and Y5499 and $C$. kefyr Y83 did not grow in the serum, nor were these strains killed in serum, indicating that these strains were resistant to complement attack but unable to grow in serum. C. albicans NCYC 1473, NCYC 1467 and Y5499 produced hyphae when incubated in serum.

Fig. 3 demonstrates that all Candida strains bound and activated complement component C3. Several C3 activation fragments were released from the surface of the strains. Fragments of $195 \mathrm{kDa}$ corresponded to the $\mathrm{C} 3 \mathrm{c}$ fragment of $\mathrm{C} 3$; fragments of $105 \mathrm{kDa}$ corresponded to $\mathrm{C} 3 \mathrm{~b}$; fragments $75 \mathrm{kDa}$ corresponded to the common $\beta$ chain of $\mathrm{iC} 3 \mathrm{~b}$ and $\mathrm{C} 3 \mathrm{~b}$; fragments of $67 \mathrm{kDa}$ and $40 \mathrm{kDa}$ corresponded to $\mathrm{iC} 3 \mathrm{~b}$; fragments of $33 \mathrm{kDa}$ corresponded to $\mathrm{C} 3 \mathrm{~d}$.

\section{Survival of Candida spp. in the presence of PMNLS}

Three strains were killed in the presence of PMNLs (Table 3), while all other strains were able to survive.

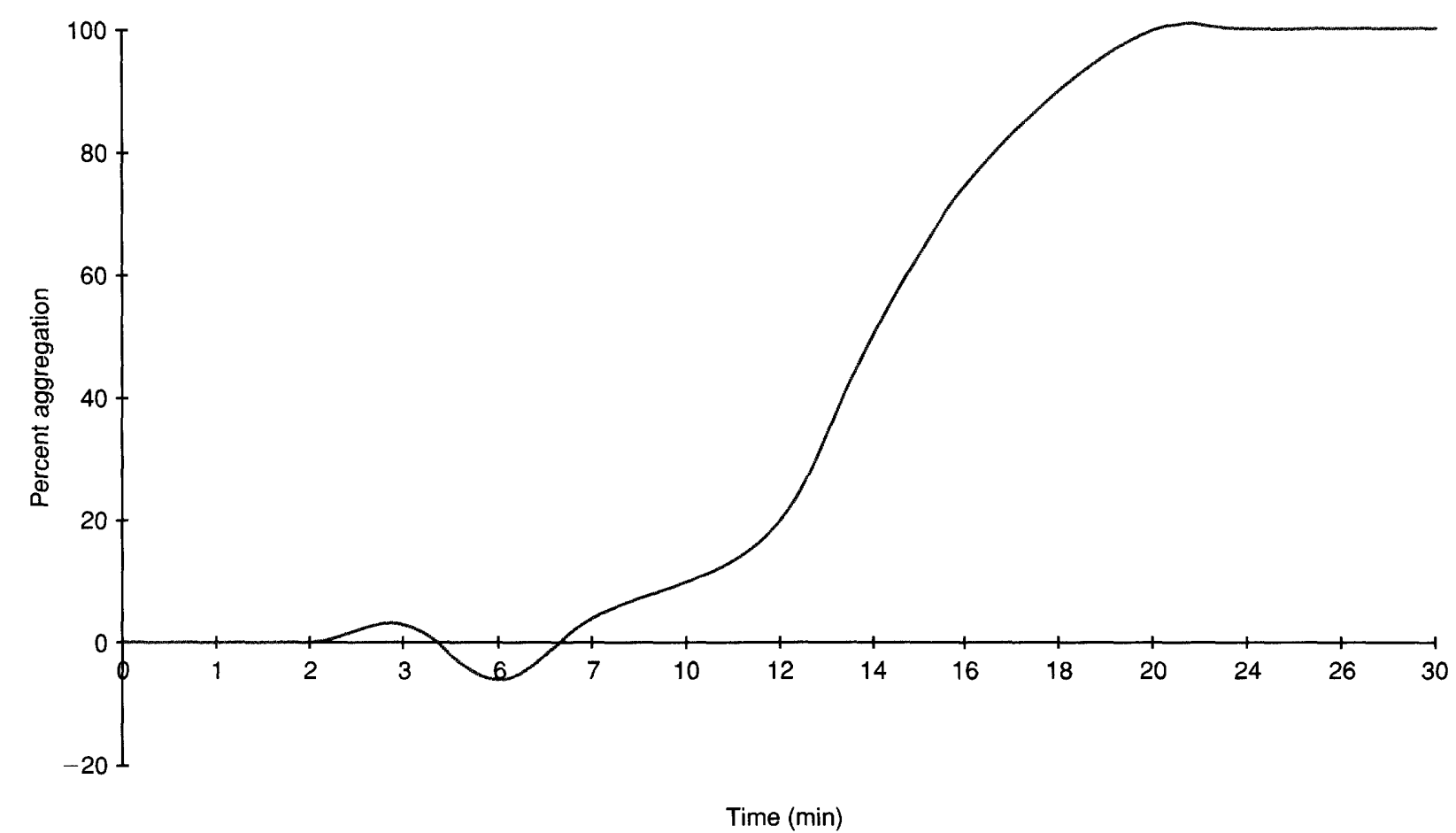

Fig. 1. The aggregation of platelets in the presence of $C$. tropicalis Y9. 
Table 3. The ability of Candida spp. to survive in the presence of complement, platelets and whole blood

\begin{tabular}{llcc}
\hline & \multicolumn{3}{c}{ Mean (SD) survival (\%) in* } \\
\cline { 2 - 4 } Species and strain no. & serum & PRP & PMNLs \\
\hline C. albicans NCYC 1473 & $96^{\mathrm{H}}(4)$ & $99^{\mathrm{H}}(0)$ & $105(3)$ \\
C. albicans NCYC 1467 & $95^{\mathrm{H}}(3)$ & $100^{\mathrm{H}}(2)$ & $93(5)$ \\
C. albicans Y5499 & $98^{\mathrm{H}}(2)$ & $100^{\mathrm{H}}(3)$ & $93(2)$ \\
C. albicans (stellatoidia) Y535 & $180(13)$ & $40(10)$ & $25(5)$ \\
C. tropicalis Y9 & $160(17)$ & $54(8)$ & $37(10)$ \\
C. parapsilosis Y316 & $140(26)$ & $100(1)$ & $130(5)$ \\
C. guilliermondii Y324 & $135(3)$ & $120(7)$ & $105(12)$ \\
C. krusei Y301 & $160(8)$ & $100(0)$ & $104(5)$ \\
C. kefyr Y83 & $104(13)$ & $103(3)$ & $22(9)$ \\
\hline
\end{tabular}

PRP, platelet rich plasma; PMNLs, polymorphonuclear leucocytes; $H$, hyphal production. *Survival: $100 \%=$ the same number of $\mathrm{cfu} / \mathrm{ml}$ at $\mathrm{T}=0 \mathrm{~h}$ and $\mathrm{T}=4 \mathrm{~h}$; decreasing numbers indicates cell death, increasing numbers indicates cell growth. Survival in the presence of serum is a measure of the ability of strains to evade the complement pathway.

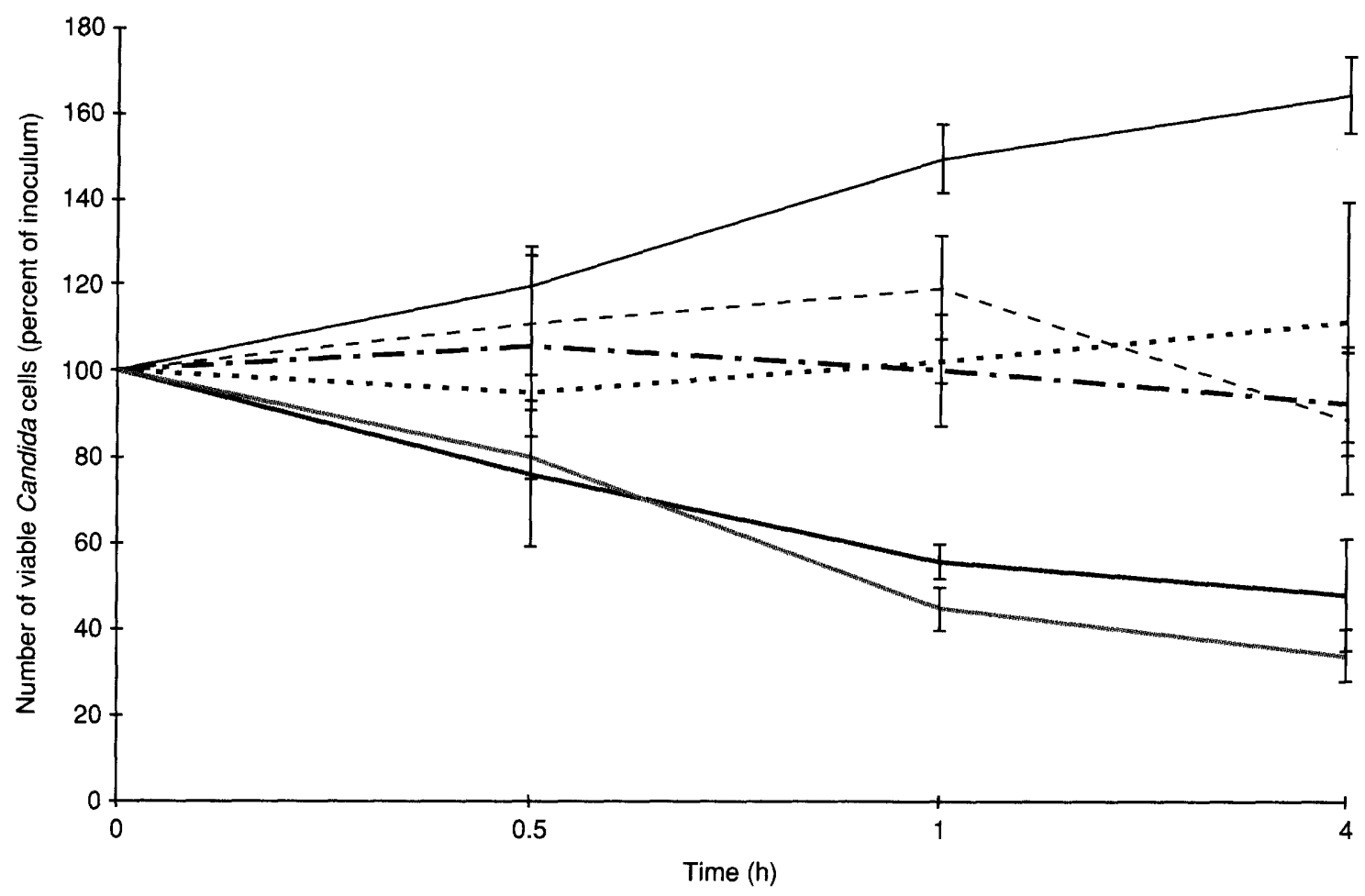

Fig. 2. The interaction of $C$. albicans NCYC 1473 and C. tropicalis Y9 with platelet-rich plasma (PRP), complement and polymorphonuclear leucocytes (PMNLs). The viability of the cells was determined after incubation for up to $4 \mathrm{~h}$ by Miles and Misra plate assays. NCYC 1473 + complement, - - -; NCYC 1473 + PRP, - - -; NCYC 1473 + PMNL, - - -; Y9 + complement, ; Y9 + PRP, —; Y9 + PMNL,

Generally, the ability of strains to survive in the presence of PMNLs mimicked their survival in plateletrich plasma, and the correlation coefficient was statistically significant $(\mathrm{p}=0.048)$.

\section{Release of inflammatory mediators}

Table 4 shows the production of inflammatory mediators from PMNLs or platelets by the different Candida strains. No strain induced the release of leukotriene $\mathrm{B}_{4}$. All strains, with the exception of $C$. parapsilosis $\mathrm{Y} 316$, induced the release of IL- 8 from PMNLs, usually showing an increase in the amount of
IL-8 after incubation for $4 \mathrm{~h}$. Certain strains were able to induce IL-8 release from platelets. Of the strains tested, only C. albicans NCYC 1467 and C. albicans (stellatoidia) Y523 were able to induce the release of IL-1 $\beta$ from PMNLs.

\section{Discussion}

This investigation has clearly demonstrated that Candida spp. are able to aggregate human platelets. While previous studies have shown that $C$. albicans can interact with platelets and platelet-fibrin clots $[9$, 


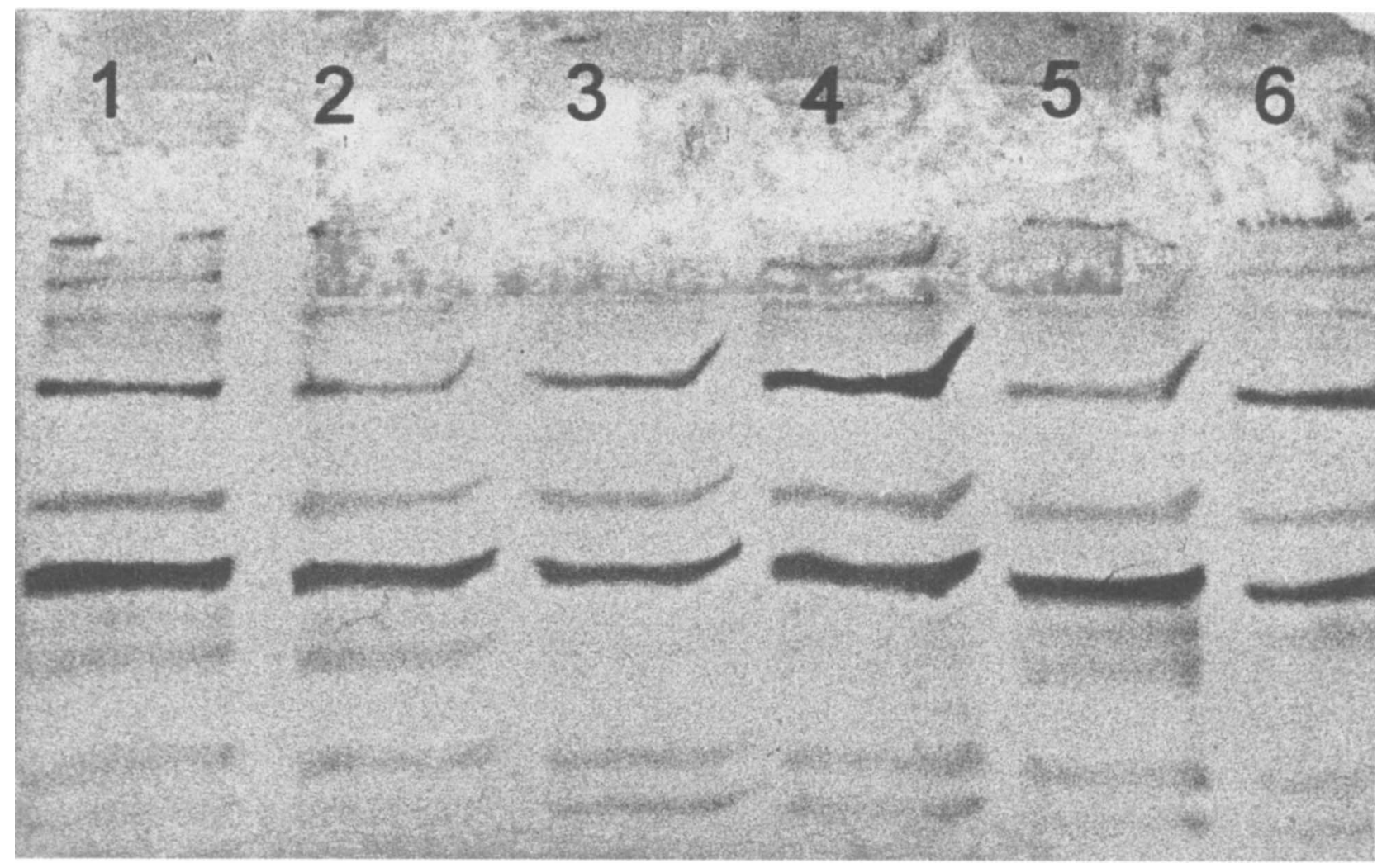

Fig. 3. Complement peptides on the surface of Candida strains after incubation with serum. Lane 1, C. albicans NCYC $1473 ; 2$, C. albicans NCYC 1467; 3, C. parapsilosis Y316; 4, C. tropicalis Y9; 5, C. albicans Y5499; 6, C. kefyr Y83.

Table 4. The induction of inflammatory mediators from PMNLs or platelets during incubation with Candida strains

\begin{tabular}{|c|c|c|c|c|c|}
\hline \multirow[b]{3}{*}{ Species and strain no. } & \multicolumn{5}{|c|}{ Mean $(\mathrm{SD})$ mediator concentration $(\mathrm{pg} / \mathrm{ml})$} \\
\hline & \multirow{2}{*}{$\begin{array}{l}\text { PMNLs incubated } \\
\text { for } 30 \text { min } \\
\text { IL-8 }\end{array}$} & \multicolumn{2}{|c|}{ PMNLs incubated for $4 \mathrm{~h}$} & \multirow{2}{*}{$\begin{array}{c}\text { Platelets incubated } \\
\text { for } 30 \mathrm{~min} \\
\text { IL-8 }\end{array}$} & \multirow{2}{*}{$\begin{array}{l}\text { Platelets incubated } \\
\text { for } 4 \mathrm{~h} \\
\text { IL-8 }\end{array}$} \\
\hline & & IL-8 & $\mathrm{IL}-1 \beta$ & & \\
\hline C. albicans NCYC 1473 & $59(12)$ & 0 & ND & $57(31)$ & 0 \\
\hline C. albicans NCYC 1467 & $129(32)$ & $287(34)$ & $60(6)$ & $44(15)$ & 0 \\
\hline C. albicans Y5499 & 0 & $517(102)$ & ND & 0 & 0 \\
\hline C. albicans (stellatoidia) Y523 & $124(17)$ & $85(3)$ & $55(18)$ & 0 & 0 \\
\hline C. tropicalis $\mathrm{Y} 9$ & 0 & 565 (194) & ND & 0 & $76(43)$ \\
\hline C. parapsilosis Y316 & 0 & 0 & ND & 0 & 0 \\
\hline C. krusei $\mathrm{Y} 301$ & $269(48)$ & $291(45)$ & ND & 0 & $59(3)$ \\
\hline C. kefyr $\mathrm{Y} 83$ & $85(2)$ & $847(201)$ & 0 & 0 & 0 \\
\hline C. guilliermondii $\mathrm{Y} 324$ & $108(51)$ & $351(49)$ & 0 & 0 & $36(32)$ \\
\hline
\end{tabular}

No strain stimulated the release of $\mathrm{LTB}_{4}$ from PMNLs. ND, not determined.

17], it has generally been accepted that whole yeast cells are unable to aggregate platelets whereas cell fragments can $[18,19]$. The present study confirms these findings, as $C$. albicans was the only species unable to aggregate platelets. This study is the first to demonstrate that other species of Candida are able to aggregate platelets. True platelet aggregation was occurring, as the specific inhibitors of platelet aggregation, EDTA that chelates cations, apyrase that reduces the availability of $\mathrm{ADP}$, quinacrine that inhibits the cyclo-oxygenase pathway and imipramine that affects platelet membrane stability, inhibited the aggregation process. Of interest was the fact that platelets derived from different blood group donors were equally able to be aggregated by the yeasts, indicating that blood group sugars are probably not involved in the platelet-Candida interactions, although they are involved in adhesion of Candida spp. to epithelial surfaces [19].

A recent publication focused attention on the role of complement in the aggregation of platelets by streptococci [10], with the assembly of the membrane attack complex (C5b-9) on the surface of the bacteria being hypothesised as a key to allowing platelet aggregation. The current study examined Candida cells for their ability to activate complement by measuring their survival in serum and the molecular 
nature of the C3 deposited on the surface of the fungi. No Candida spp. were killed in serum, indicating that either the membrane attack complex of complement is not able to damage Candida cells or that Candida cells do not allow complement activation to proceed to this terminal stage. Complement $\mathrm{C} 3$ was deposited on the surface of all strains of Candida and similar fragments were generated. The current study did not show evidence that complement, or C3 alone, is responsible for the aggregation of platelets by Candida spp., but - as with the streptococci [10] it is possible that complement together with another unidentified plasma component may mediate platelet aggregation by Candida spp. Such plasma components may be fibrinogen, fibronectin or vitronectin, all of which have been shown to bind to platelets [20-22] and can attach to Candida cells [9, 23].

There was an apparent discrepancy between the finding that $C$. albicans strains did not aggregate platelets and yet this species is the most commonly isolated Candida spp. from cases of endocarditis $[1,5,6]$. It has been stated that the ability of micro-organisms, in particular $S$. sanguis, to aggregate platelets is associated with a more virulent clinical disease [24], even though it is known that activation of platelets can release antimicrobial proteins [13]. These microbicidal proteins, PMPs, have been shown to be active against $C$. albicans [13]. Thus, the present study determined whether the activation of platelets by Candida species could induce killing of the fungal cells. The incubation of certain strains with platelets did reduce the numbers of viable cells and other strains were not able to grow in PRP, but could grow in serum, indicating the microbistatic nature of PRP. These findings were to some extent dependent on the ability of the fungi to aggregate platelets, as $C$. albicans did not aggregate platelets and was not killed but prevented from growing in platelet-rich plasma. Thus, we conclude that, for Candida species, platelet aggregation by Candida cells may allow the host to clear the fungi more readily.

Incubation of Candida spp. with PMNLs led to a similar pattern of survival or killing as incubation in platelet-rich plasma, indicating that similar mechanisms may be involved. The microbicidal proteins of platelets have been shown to be cationic peptides $[13,25]$ and the defensins of human neutrophils are also cationic proteins [12].

In the blood stream, or as part of a thrombotic vegetation, Candida cells will come into contact with PMNLs. It has been noted that neutropenic patients (with reduced numbers of PMNLs) are highly susceptible to the development of systemic candidosis [14] indicating the importance of PMNLs in defending the body agains Candida spp. In the present study $C$. tropicalis, C. albicans (stellatoidia) and C. kefyr were killed in the presence of PMNLs and the C. albicans strains were unable to grown in their presence. The activation of complement by Candida spp. and the production of $\mathrm{C} 3$ fragments on cell surfaces indicates that the chemotactic fragment $\mathrm{C} 5 \mathrm{a}$ is probably produced by Candida cells in blood. This will recruit PMNLs to sites on infection. The present study also demonstrated that Candida cells can stimulate PMNLs to produce the inflammatory cytokines IL-8 and, to a lesser extent, IL- $1 \beta$. IL- 8 is a member of the $\alpha$ chemokine family, a specialised protein that attracts PMNLs. This attraction leads to the accumulation of PMNLs at the site of infection and promotes the development of inflammation. IL-8 also activates PMNLs, increasing their release of tissue destructive substances such as proteases [26]. This activation of tissue destruction may contribute to the destruction of heart that occurs during endocarditis. The current study also demonstrated that interaction of Candida with platelets can also release IL- 8 . Thus, IL- 8 can be produced from platelets, PMNLs and endothelial cells [8] upon stimulation with yeast cells.

In conclusion, this study has shown for the first time that non-albicans Candida spp. can aggregate platelets. Certain strains were killed in the presence of platelets, presumably by the release of platelet microbicidal proteins. Furthermore, strains were able to activate complement and activate PMNLs to produce the chemokine IL-8, increasing the recruitment of PMNLs to the site of infection and potentially contributing to tissue destruction by the activation of the PMNLs and release of proteases.

This study was supported in part by a grant from the Australian Federal Government under the Cooperative Research Centres Programme. The Clive and Vera Ramacioti Foundations grant (to D.W.S.H.) supported the purchase of the platelet aggregometer. We thank the Sydney Blood Bank for providing blood samples.

\section{References}

1. Odds FC. Candida and candidosis, 2nd edn. London, Bailliere Tindall. 1988: 175-180.

2. MacFarlane TW, Samaranayake LP. Fungal infections. In: Clinical oral microbiology. London, Wright. 1989: 122-139.

3. Scheld WM, Sande MA. Endocarditis and intravascular infections. In: Mandell GL, Bennett JE, Dobin R (eds) Principles and practice of infectious diseases, vol 1, 4th edn. New York, Churchill Livingstone. 1995: 740-783.

4. Walsh TJ, Pizzo PA. Treatment of systemic fungal infections: recent progress and current problems. Eur J Clin Microbiol Infect Dis 1988; 7: 460-475.

5. Reyes MP, Lerner AM. Endocarditis caused by Candida species. In: Body GP, Fainstein V (eds) Candidiasis. New York, Raven Press. 1985: 203-209.

6. Hallum JL, Williams TW. Candida endocarditis. In: Bodey GP (ed) Candidiasis: pathogenesis, diagnosis and treatment. New York, Raven Press. 1993: 257-369.

7. Jakab E, Paulsson M, Ascencio F, Ljungh A. Expression of vitronectin and fibronectin binding by Candida albicans yeast cells. APMIS 1993; 101: 187-193.

8. Filler SG, Pfunder AS, Spellberg BJ, Spellberg JP, Edwards JE. Candida albicans stimulates cytokine production and leukocyte adhesion molecule expression by endothelial cells. Infect Immun 1996; 64: 2609-2617.

9. Maisch PA, Calderone RA. Role of surface mannan in adherence of Candida albicans to fibrin-platelet clots formed in vitro. Infect Immun 1981; 32: 92-97. 
10. Ford I, Douglas CWI, Heath J, Rees C, Preston FE. Evidence for the involvement of complement proteins in platelet aggregation by Streptococcus sanguis NCTC 7863. $\mathrm{Br} J$ Haematol 1996; 94: 729-739.

11. Lehrer RI, Barton A, Daher KA, Harwig SSL, Ganz T, Selsted ME. Interaction of human defensins with Escherichia coli. Mechanisms of bactericidal activity. J Clin Invest 1989; 84: $553-561$.

12. Spitznagel JK. Antibiotic proteins of human neutrophils. $J$ Clin Invest 1990; 86: 1381-1386.

13. Yeaman MR, Tang Y-Q, Shen AJ, Bayer AS. Selsted ME. Purification and in vitro activities of rabbit platelet microbicidal proteins. Infect Immun 1997; 65: 1023-1031.

14. Domer JE, Lehrer RI. Introduction to Candida: systemic candidiasis. In: Murphy JW, Freidman H, Bendinelli M (eds) Fungal infections and immune responses. New York, Plenum Press. 1993: 49-116

15. Miles AA, Misra SS, Irwin JO. The estimation of the bactericidal power of the blood. $J$ Hyg 1938; 38: 732-748.

16. Gordon DL, Rice J, Finlay-Jones JJ, McDonald PJ, Hostetter MK. Analysis of C3 deposition and degradation on bacterial surfaces after opsonization. J Infect Dis 1988; 157: 697--704.

17. Klotz SA, Harrison JL, Misra RP. Aggregated platelets enhance adherence of Candida yeasts to endothelium. J Infect Dis 1989; 160: 669-677.

18. Skerl KG, Calderone RA, Sreevalson T. Platelet interactions with Candida albicans. Infect Immun 1981; 34: 938-943.
19. Cameron BJ, Douglas LJ. Blood group glycolipids as epithelial cells receptors for Candida albicans. Infect Immun 1996; 64: 891-896.

20. Gartner TK, Bennett JS. The tetrapeptide analogue of the cell attachment site of fibronectin inhibits platelet aggregation and fibrinogen binding to activated platelets. $J$ Biol Chem 1985; 260: $11891-11894$

21. Mohri H, Ohkubo T. How vitronectin binds to activated glycoprotein IIb-IIIa complex and its function in platelet aggregation. Am J Clin Pathol 1991; 96: 605-609.

22. Preissner KT, Jenne D. Structure of vitronectin and its biological role in homeostasis. Thromb Haemost 1991; 66: 123-132.

23. DeMuri GP, Hostetter MK. Evidence for a $\beta_{1}$ integrin fibronectin receptor in Candida tropicalis. J Infect Dis 1996; 174: $127-132$.

24. Herzberg MC, MacFarlane GD, Gong $\mathrm{K}$ et al. The platelet interactivity phenotype of Streptococcus sanguis influences the course of experimental endocarditis. Infect Immun 1992; 60: 4809-4818.

25. Koo S-P, Yeaman MR, Bayer AS. Staphylocidal action of thrombin-induced platelet microbicidal protein is influenced by microenvironment and target cell growth phase. Infect Immun 1996; 64: 3758-3764.

26. Oppenheim JJ, Zachariae COC, Mukaida N, Matsushima K. Properties of the novel proinflammatory supergene "intercrine" cytokine family. Annu Rev Immunol 1991; 9: 617-648. 